\title{
Does a Smile Open All Doors? Understanding the Impact of Appearance Disclosure on Accommodation Sharing Platforms
}

\author{
Olga Abramova \\ University of Potsdam, Germany \\ oabramov@uni-potsdam.de
}

\begin{abstract}
Online photographs govern an individual's choices across a variety of contexts. In sharing arrangements, facial appearance has been shown to affect the desire to collaborate, interest to explore a listing, and even willingness to pay for a stay. Because of the ubiquity of online images and their influence on social attitudes, it seems crucial to be able to control these aspects. The present study examines the effect of different photographic self-disclosures on the provider's perceptions and willingness to accept a potential cosharer. The findings from our experiment in the accommodation-sharing context suggest social attraction mediates the effect of photographic selfdisclosures on willingness to host. Implications of the results for IS research and practitioners are discussed.
\end{abstract}

\section{Introduction}

People often encounter situations in which they only have very little information about the individuals they are going to interact with [71]. To handle such situations with a high level of uncertainty, interactants have been demonstrated to form first impressions swiftly [1-3]. Facial appearance is commonly the most prominent source of information in such moments and thus contributes substantially to spontaneous personality judgments (e.g. [4]). In the era of the ubiquitous Internet with online services gradually dislodging traditional offline transactions, a profile photo is often considered one's representative in the digital world [5].

This could not be truer than for peer-to-peer sharing platforms where users can offer or request sharing a resource: for instance, a place to stay (Airbnb, HomeAway), a parking place (ParkatmyHouse) or a trip (BlaBlaCar, Flinc). Whether referred to as the "access economy," "collaborative consumption," or "sharing economy," these kinds of platforms are anticipated to grow to more than $\$ 300$ billion by 2025 , from $\$ 14$ billion in 2014 [6]. In contrast to e-commerce which implies significant regulations for sellers and typically no personal interaction with the vendor for consumers, sharing economy transactions are often not subject to a strict procedure along with personal interaction and thus impose higher risks. As such, $52 \%$ of respondents cite personal safety as the most significant concern, and 58\% of US and UK consumers believe risks of the sharing economy override its benefits [7]. Hence, as part of their uncertainty-reducing strategy, platforms like Airbnb or BlaBlaCar request users to disclose personal information to the system and other peers to register, identify themselves or to allow the system to work as designed [8]. This, in turn, offers peers some visual cues they can rely on when deciding on whether to accept a sharing offer or not.

Providers' and consumers' photos on sharing economy platforms are assumed to satisfy the need for personal contact and social presence. Past studies proffered individuals are more willing to collaborate with and trust trustworthy-looking actors [910]. At the same time, another stream of research reports different forms of discrimination taking place on sharing platforms, thus hinting at the backfiring effects of selfdisclosure [e.g., 50, 72]. So far, there exists evidence on how the host's photos govern interest to explore a listing of prospective customers on Airbnb [53-54]. On the other hand, to start a sharing transaction, the resolution is made by a host by confirming or declining a request. In this paper, we, therefore, take a host's perspective and report how consumer's photographic self-disclosure is a critical determinant of the provider's perception of social attractiveness and willingness to accept a potential co-sharer in the accommodation-sharing context (i.e., a guest). We define profile photographs as images on the peer-to-peer sharing platform used to represent one's physical appearance. The primary research question addressed in the present study is: what impact do different presentation strategies have on the host's decision to accept a request sent from a stranger? To answer this question, we build on the ecological theory of social perception which assumes that surrounding objects and environment offer affordances (e.g., danger, injury or pleasure) for a person or animal and therefore are needed to be perceived [11].

The remainder of the paper is organized as follows. In the following section, we summarize related work and derive hypotheses that link photographic self- 
disclosure strategies with the social attractiveness and the probability to be accepted as a guest. Next, the methodology and results of the empirical study are presented. Implications of our findings for IS research and practitioners are discussed in the concluding part.

\section{Related Work}

The ecological approach to social perception, rooted in Gibson's theory of object perception [12], suggests that the physical appearance reveals structural invariants specific to a person such as ability and character. As such, people's faces give adaptive information about the social interactions they afford. In most cases, the 'cute' baby appearance calls for approach and protective responses [13-14]; an angry expression evokes protective responses and aversion [15-16]. Recent studies evidenced the temptation to judge strangers by their faces is hard to resist across a variety of contexts and disciplines such as marketing [55-58], psychology [59-61], neuroscience [62-63] and information systems [53-54, 64-67]. Previous studies contend that participants are more willing to collaborate and trust actors with trustworthy-looking faces [9-10]. Surprisingly, sometimes a look overshadows reputation: in an experiment, people were willing to invest more money in a person with a better-looking photo regardless of their good or bad credit history [17].

In sharing settings, with research mainly focused on the consumer's perspective, personal images appear to govern their choices considerably. For instance, potential guests are willing to pay more for listings posted by a trustworthy-looking host [53]. Hosts' photos with positive or neutral facial expressions yield interest towards a web page and increase the likelihood to rent in a peer-to-peer marketplace [54]. A negative facial expression or an absence of a photo (default head silhouette) decreases the interest to explore an Airbnb web page and the booking probability. Multiple records of racial and other discrimination on sharing platforms also allude to the impact of appearance on judgments $[50,72]$. Recognizing the priority of consumer's interest and initiative in a deal, it is the host who makes the final decision by accepting or rejecting a request. Considering the peer-to-peer nature of sharing transaction, we assume the previous findings also apply when it comes to the host's decisions regarding a potential guest. Taken together, we hypothesize:

H1: the guest's photographic self-disclosure strategy has an impact on the host's willingness to accept a guest.

The positive effect of the appearance is often attributed to attractiveness perceptions or in other words, a consequence of relying on "what is beautiful is good" heuristic when evaluating an unknown person. The so-called "beauty/attractiveness premium" suggests that good-looking individuals are assumed to own other unrelated positive features as a result of their attractiveness (e.g. [18]). For instance, deciding on a new employee, attractive job applicants were preferred over unattractive applicants [19-20]. Furthermore, attractive individuals have been scored as more persuasive communicators than unattractive counterparts [21], receive better offers for starting salary [22], better performance evaluations [23], better ratings for admission to academic programs [23], better offers when bargaining [25], and even more favorable judgments in trials [26].

The examples above do not count on beauty similar to one of the advertising models but instead refer to social (interpersonal) attractiveness that can be defined as "a motivational state in which a person is predisposed to think, feel, and usually behave positively toward another person" [27]. Given its complex nature, social (interpersonal) attractiveness is theorized to have three components: 1) task attraction, reflecting willingness to work with someone to accomplish goals 2) social (relational) attraction, meaning the desire to "hang out" with someone 3) physical attraction, when we like how people look.

In the sharing economy context, the social component is given particular importance. In contrast to e-commerce, here a provider and a consumer both cooperate to share a resource temporally. Therefore, compatibility and mutual attraction determine, to a large extent, how enjoyable their joint consumption will be. Prior research substantiates social motive to be one of the most important factors when deciding whether to use a sharing economy service or not [28-29, 68]. Given that, we assume:

H2: the relationship between guest's photographic selfdisclosure strategy and host's willingness to accept is mediated by social attractiveness.

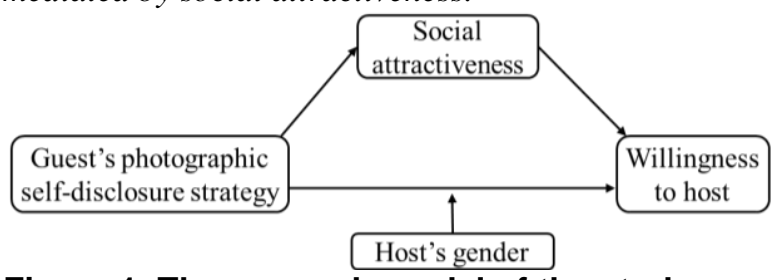

Figure 1. The research model of the study

In the literature, it is well cited that women better detect emotions in nonverbal communication [73-75]. Females report more accurate judgments, even when only subtle facial cues of emotion are present [75]. On sharing economy platforms, women demonstrated a stronger reaction to positive and negative facial stimuli [54]. From this discussion, we hypothesize: H3: the impact of photographic self-disclosure on 
willingness to host is stronger for female hosts than for male hosts.

\section{Methodology}

\subsection{Experiment design and flow}

To determine the impact of different guest's photographic self-disclosure strategies on willingness to host, a 2 x 4 experiment was designed, where the applicant's photo and the guest's gender (male vs. female) were manipulated. The methodological approach was inspired by the PhotoFeeler study [5] where different characteristics of profile photos were examined. Hence, in our study pictures with dark editing, people wearing sunglasses and zoomed-in pictures showing only part of the face combined with a serious look were included. Finally, as a contrast condition, pictures with smiling (laughing) persons were tested.

In order to understand the landscape of guests' profiles, 50 guest profiles who sent a request for a real private room listing in Berlin via the Airbnb platform [34] were screened. Treatment conditions were formulated based on this exploration and were pretested with two subjects. The photos were shot privately. Necessary adjustments to improve contrasts were made based on the elicited feedback (Table 1).

After accessing the survey (step 1), participants were first asked to imagine that they have a spare room they would like to rent out at one of the peer-to-peer sharing platforms like Airbnb, 9flats or Wimdu. The exact accommodation platform was not specified on purpose to eliminate the effect of the reputation bias of the existing companies. Respondents were presented with the sample picture of a room to better plunge into a scenario. The photos of the apartment were shot privately and represent a real Airbnb listing ${ }^{1}$. According to the introduction scenario, the respondent's host account was set up on the platform, and luckily, there were already a few requests from people who wanted to rent this free room.

In step 2, participants were randomly assigned to one of 4 treatment conditions with male guests (smiling, serious with sunglasses, serious zoomed-in, and serious dark-edited). They were presented with the profile of a potential guest, including a picture and a description text similar to the way it is done on Airbnb.com or 9flats.com. Guest's attributes were chosen premised on our exploration of existing profiles. The section "About me" was filled with the neutral text "Hi! I am Christian/Julie, a student from Hannover, Germany.

1 Pictures of a real Airbnb listing of one of the researchers
And I love to travel!" Membership was set to "since January 2016", occupation to "student." Further, the icons "verified e-mail address" and "verified phone number" were presented in the profile since they were frequently present attributes $(88 \%$ and $96 \%$ of cases, correspondingly) in our pre-study sample. Upon viewing the profile of the potential guest, respondents had to express their willingness to host this person by answering "Would you host this person?" on a 7-point Likert scale ( $1=$ strongly agree, $7=$ strongly disagree). Social attractiveness scale was based on [27] and included the following four items: 1) "How likely is it that this person could be a friend of yours?" 2) "Do you trust this person?" 3) "Do you think this person is likable?" 4) "Do you think this person is reliable?" (7point Likert scale $(1=$ strongly agree, $7=$ strongly disagree).

\section{Table 1. Treatment conditions}

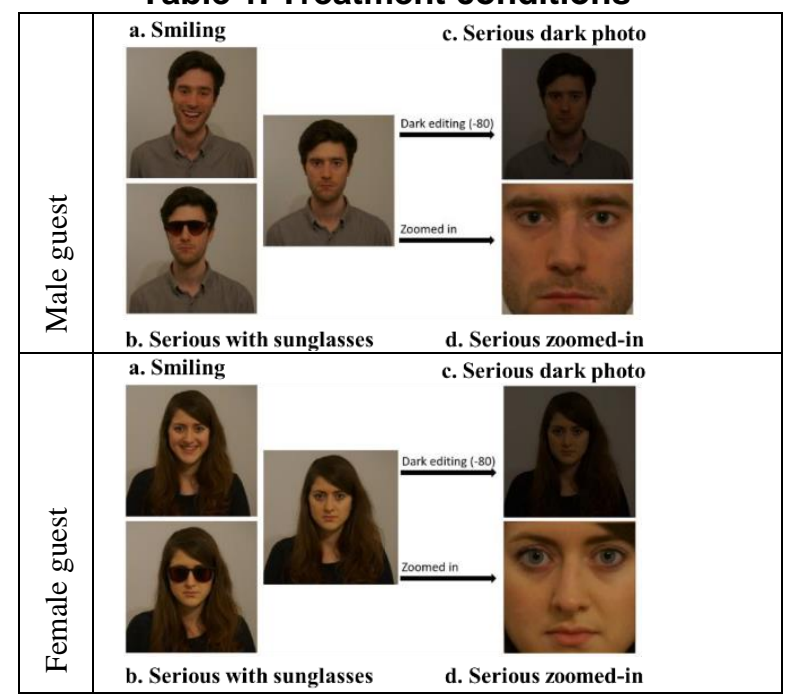

In step 3, respondents were randomly assigned to one of 4 treatment conditions with a female guest and evaluated her profile with the same questions as in step 2.

In step 4, control variables such as age, respondent's gender, income, experience as a guest, experience as a host, income from renting out on sharing platforms per year, the importance of particular guest's characteristics and general propensity to trust based on [37] were measured. The latter was operationalized with the following items: 1) "In general people care about the well-being of others"; 2) "Most people are concerned about other people's problems"; 3) "In general people are helpful and do not only care about their own needs"; 4) "Most people keep their promises"; 5) "Many people try to support their words with actions"; 6) "Most people are honest" with answers on a 7-point Likert scale (1=strongly agree, $7=$ strongly disagree $)$. 


\subsection{Sampling and sample characteristics}

Survey participants were recruited through the various social media channels like Facebook timeline posts, Facebook group posts, Airbnb host groups, Couchsurfing groups, LinkedIn and Xing posts. No remuneration was claimed. A total of 650 respondents accessed the online survey, out of which 270 have completed it.

The survey was offered in English and German; $41 \%$ selected English, 59\% German. 58\% of all participants currently live in Germany, $6 \%$ in the US. Another 14\% of all participants live in Europe (w/o Germany) and $19 \%$ in other non-European countries (w/o US). 36.7\% $(\mathrm{n}=99)$ of the respondents in the sample are male, $58.5 \%$ female $(n=158), 1.1 \%(n=3)$ other, and $3.7 \%(n=10)$ did not specify. The average participant is 26 years old based on a median value (mean=26.5). Half of all participants are students, $30 \%$ hold a university entrance diploma (Abitur), 33\% a bachelor's degree and 24\% a master's degree.

$34 \%$ ( $\mathrm{n}=91$ ) of the participants have used a sharing accommodation platform as a guest, and $26 \%(\mathrm{n}=69)$ hosted other people. According to the self-reported numbers, the median number of previous stays by an experienced guest is 3 , and the mean value is 6 . Among those who hosted strangers, the median number of visits equals 10 , and the mean is 54 , hinting at the regular renting-out practice on a sharing platform in our sample. For 25 hosts, the profit gained through a platform is a part of the regular income. If participants make money via a sharing $(\mathrm{n}=25)$ they earn on average $€ 587$ per month; $35 \%$ of them obtain less than $€ 100,46 \%$ bring in between $€ 100$ and $€ 1000,10 \%$ gain between $€ 1000$ and $€ 2000$ and another $10 \%$ even more than $€ 2000$. Most of the participants $(75 \%)$ have made no bad experiences with hosting guests on a sharing platform so far, $11 \%$ encountered unpleasant situations once, $13 \%$ a few times and $2 \%$ several times. $85 \%$ of respondents $(n=230)$ are open to hosting both male and female travelers, while $14 \%(n=37)$ host only females and about $1 \%(\mathrm{n}=3)$ accept only male guests.

The overwhelming majority of respondents express the importance of neatness $(94.8 \%, \mathrm{n}=255)$ when the guest leaves everything clean and tidy behind. 65\% $(n=173)$ pointed out the significance of interaction (e.g., conversations, activities). Having the same hobbies and interests is not a must: $36.6 \%$ of respondents expressed the importance of this factor, for $39.9 \%$ it is rather unimportant while $23.5 \%$ are indifferent to this factor.

Regarding the guest's profile characteristics, hosts in our sample believe the profile picture to be the most essential attribute ( $88 \%$ expressed as "very important", "important" or "rather important") followed by text description (88\%), reviews from past trips $(85.7 \%)$ and a verified e-mail address (82.8\%). Link to SNS account and information about school/work seem not to influence hosts' decision. These attributes count for $44.9 \%$ and $41.4 \%$ respectively, while roughly the same share of respondents believe these are insignificant (35.2\% and $38.7 \%$ respectively) or are indifferent (19.9\% for both cases).

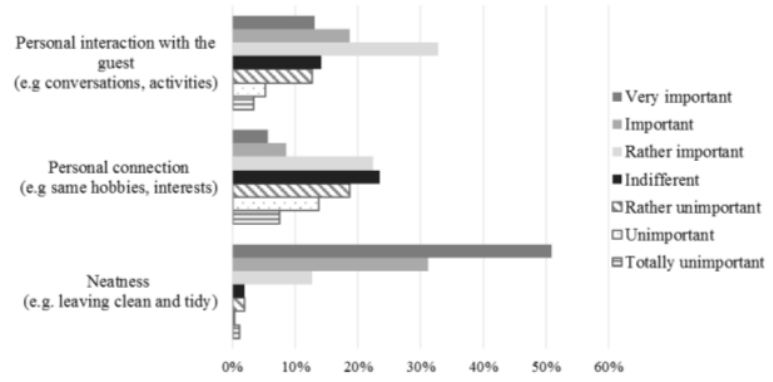

Figure 2. The importance of guests' characteristics

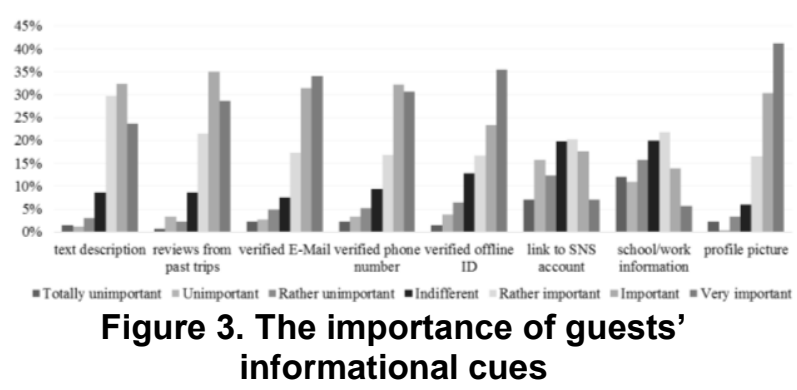

To ensure the effectiveness of manipulation, we primarily relied on behavioral measures. First, the survey was designed as interesting and compact as possible. The pre-tested and declared length was $5 \mathrm{~min}$, the actual mean duration comprised $8.1 \mathrm{~min}(\mathrm{SD}=4 \mathrm{~min}$ $24 \mathrm{sec}$ ). The main questions were asked at the beginning of the survey. Second, the image changes were performed either technically (e.g., dark editing $-80 \%$, zooming in from a bust to a face-only close-up) or maintain a high degree of objectivity (e.g., presence or absence of sunglasses). As advocated by [77], behavioral measures together with pilot testing are less problematic than a prototypical manipulation check that severely intervenes the procedure.

\section{Results}

Effects on willingness to host. A two-way ANOVA revealed a main effect of guest's photographic disclosure on willingness to host for a female guest $(\mathrm{F}$ $(3,255)=15.52, \mathrm{p}<.001)$ and a male guest $(\mathrm{F}(3,258)$ $=11.41, \mathrm{p}<.001)$ sample. Our primary prediction $(\mathrm{H} 1)$ was supported: People in the different self-disclosure 
conditions reported various willingness to accept the potential guest. The main effect of the respondent's gender (female guest: $F(1,255)=0.196, p=0.658$; male guest: $\mathrm{F}(1,258)=0.30, \mathrm{p}<0.862)$ and the interaction effect (female guest: $\mathrm{F}(3,255)=0.130, \mathrm{p}=0.942$; male guest: $F(3,258)=0.800, p=0.495)$ were not significant. Thus, H3 cannot be confirmed.

Table 2. Multiple comparisons of photographic self-disclosure with Tukey's test (DV- willingness to accept)

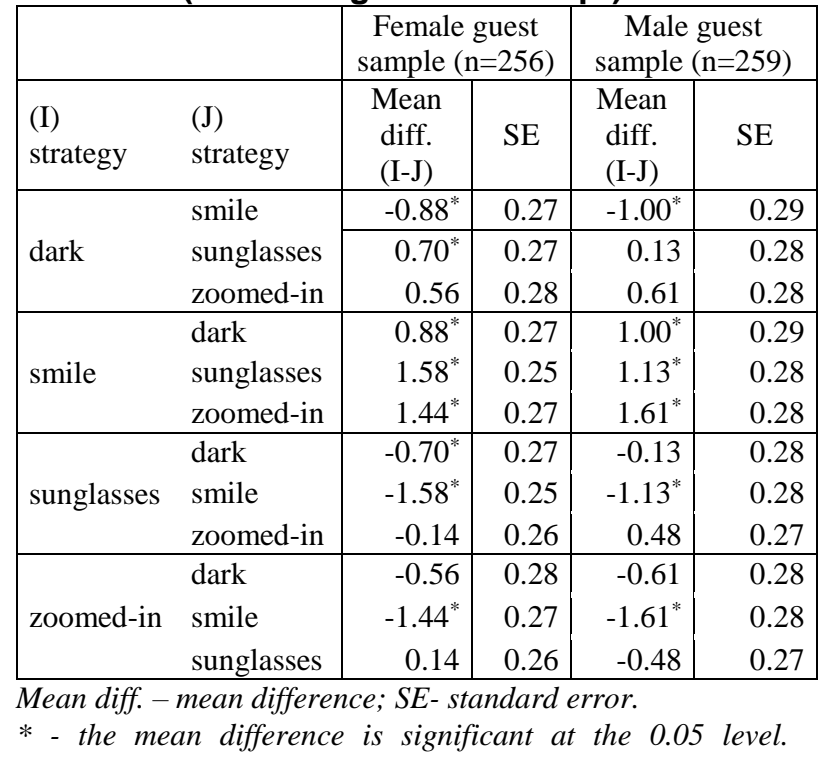

Pairwise comparison with the Tukey's multiple comparison test elaborates on the effects of each strategy. As expected, a photo with a smiling person significantly outperforms any other strategy. When confronted with a female guest, a dark photo was preferred over one with sunglasses ( $\mathrm{M}^{\text {dark }}$ $\mathrm{M}^{\text {sunglasses }}=0.7, \mathrm{p}=0.049$ ), while for a male guest the difference was not statistically significant $\left(\mathrm{M}^{\text {dark }}\right.$ $\mathrm{M}^{\text {sunglasses }}=0.13, \mathrm{p}=0.970$ ). Regardless of the guest's gender, contrasting a dark photo with a zoomed-in photo does not yield significant differences in the willingness to accept. The same is true when matching a zoomed-in image vs. a face covered with sunglasses.

Social attractiveness. Next, we evaluated the impact of guest's photographic self-disclosure on participants' perception of social attractiveness while they viewed the profile. Principal components analysis revealed that all items for the construct "Social attractiveness" loaded onto a single factor (Cronbach's Alpha $=0.92$ ); thus, we created an average score of the four items, and we refer to it simply as "social attractiveness" for the preliminary analysis. A two-way ANOVA with social attractiveness as the dependent variable revealed a main effect of photographic self-disclosure for a female guest (F (3,
$252)=27.045, \mathrm{p}<0.001)$ and a male guest $(\mathrm{F}(3,255)$ $=15.379, \mathrm{p}<0.001)$ sample. Participants perceived a smiling applicant as more socially attractive (female guest: $\mathrm{M}^{\text {smile }}=5.22, \mathrm{SD}=0.15$; male guest: $\mathrm{M}^{\text {smile }}=4.96$, $\mathrm{SD}=0.16$ ) as compared to a dark face (female guest: $\mathrm{M}^{\text {dark }}=4.11, \mathrm{SD}=0.17$; male guest: $\mathrm{M}^{\text {dark }}=3.97$, $\mathrm{SD}=0.16$ ), a face covered with sunglasses (female guest: $\mathrm{M}^{\text {sunglasses }}=3.51, \mathrm{SD}=0.14$; male guest: $\mathrm{M}^{\text {sunglasses }}=3.69$, $\mathrm{SD}=0.15$ ) or a zoomed-in image (female guest: $\mathrm{M}^{\text {zoomed- }}$ in $=3.75, \mathrm{SD}=0.16$; male guest: $\mathrm{M}^{\text {zoomed-in }}=3.61$, $\mathrm{SD}=0.15)$. The main effect of the respondent's gender (female guest: $\mathrm{F}(1,254)=0.652, \mathrm{p}=0.420$; male guest: $\mathrm{F}(1,257)=0.381, \mathrm{p}=0.538)$ and the interaction effect (female guest: $\mathrm{F}(3,252)=0.663, \mathrm{p}=0.576$; male guest: $\mathrm{F}(3,255)=0.782, \mathrm{p}=0.505)$ were not significant. Although the lines in Figure 4 intersect, the p-values suggest a model with interaction is not required to describe the main patterns in the data.

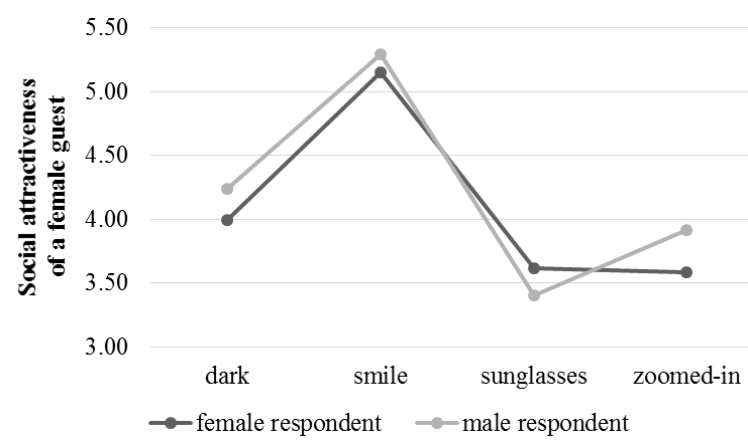

4. A. Female guest treatment

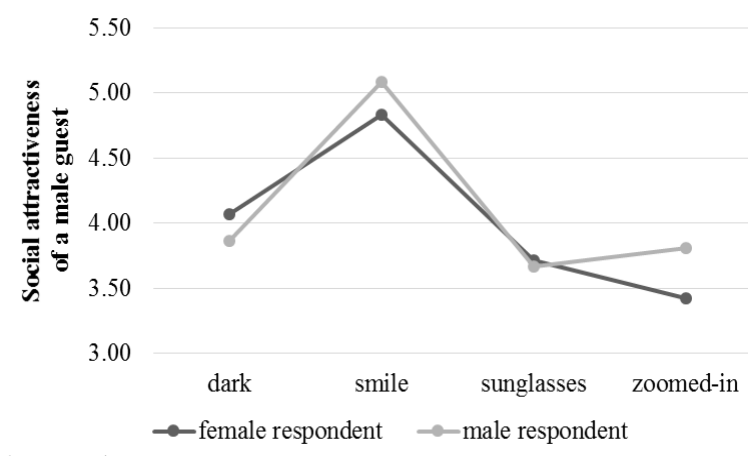

4.B. Male guest treatment

\section{Figure 4. Perception of social attractiveness for different self-disclosures}

Mediation analysis. Next, we tested whether the perception of social attractiveness mediates the effects on willingness to host. At this stage, the partial least squares (PLS) approach was chosen as a method to analyze non-normally distributed data with the limited sample size [42]. According to the Shapiro-Wilk W test, the distribution of the dependent variable „Willingness to host" significantly deviates from a normal one for 
both male guest sample $(\mathrm{P}>\mathrm{Z}=0.00072)$ and female guest sample $(\mathrm{P}>\mathrm{z}=0.00015)$. Moreover, "Social attractiveness" and "Propensity to trust" were initially measured as constructs with multiple items. SmartPLS 3.2.8 software was used [39] for the evaluation of the research model.

Table 3. Quality Criteria of Constructs

\begin{tabular}{|c|c|c|c|c|c|c|}
\hline \multirow{2}{*}{ Model } & \multirow{2}{*}{ Construct } & \multicolumn{2}{|c|}{ AVE } & \multicolumn{2}{|c|}{$\begin{array}{l}\text { Composite } \\
\text { Reliability }\end{array}$} & \multirow[t]{2}{*}{$\mathrm{CA}$} \\
\hline & & Dir. & Med. & Dir. & Med. & \\
\hline \multirow{2}{*}{$\begin{array}{l}\text { Willingness } \\
\text { to host a } \\
\text { male guest }\end{array}$} & $\begin{array}{l}\text { Social } \\
\text { attractiveness }\end{array}$ & n.e. & 0.77 & n.e. & 0.93 & 0.90 \\
\hline & $\begin{array}{l}\text { Propensity to } \\
\text { trust }\end{array}$ & \multicolumn{2}{|c|}{0.58} & \multicolumn{2}{|c|}{0.89} & 0.86 \\
\hline \multirow{2}{*}{$\begin{array}{l}\text { Willingness } \\
\text { to host a } \\
\text { female } \\
\text { guest }\end{array}$} & $\begin{array}{l}\text { Social } \\
\text { attractiveness }\end{array}$ & n.e. & 0.84 & n.e. & 0.95 & 0.94 \\
\hline & $\begin{array}{l}\text { Propensity to } \\
\text { trust }\end{array}$ & \multicolumn{2}{|c|}{0.58} & \multicolumn{2}{|c|}{0.89} & 0.86 \\
\hline
\end{tabular}

The Measurement Model (MM) was evaluated by verifying the criteria for Convergent Validity $(\mathrm{CV})$ and Discriminant Validity (DV). To ensure CV, parameters for Indicator Reliability (IR), Composite Reliability (CR) and Average Variance Extracted (AVE) were assessed. For IR, constructs should explain at least 50\% of the variance of their respective indicators. Items with factor loadings below 0.4 should be removed from the model [40]. All items in both models satisfied the criteria stated above, with loadings exceeding the threshold of 0.7 [41]; IR was assured. CR values for all constructs were higher than the required level of 0.7 , as shown in Table 3. The AVE values for all measured constructs also satisfy the necessary criteria (AVE $>0.5$ ) [42]. Finally, Cronbach's alpha (CA), a measure of Internal Consistency of construct scales, was higher than the required threshold of 0.7 for all constructs [43]. Taken together, CV can be assumed. Next, DV was assessed by ensuring that the square root of AVE for each construct was higher than the correlation between this construct and any other construct in the model [41]. This requirement was fulfilled for all constructs in our model. Taken together, we assume our MM to be wellspecified.

Structural Model (SM) was evaluated for both male and female guests. The endogenous variable in all models is the willingness to host a guest, whereas the exogenous ones are the self-disclosure strategies and, in the mediated models, the social attractiveness. The significance of the path coefficients was established based on a bootstrapping procedure. In general, we pursued the approach Baron and Kenny [76] advocate. First, the direct impact of self-disclosure strategies on willingness to host was tested. As shown in Figure 5 (model 5a), path coefficients of the self-disclosure strategies (for male guests: $b^{\text {zoomed-in }}=-0.4^{* *} ; b^{\text {dark }}=-$ $0.23 * * ; b^{\text {sunglasses }}=-0.28 * *$; for female guests: $b^{\text {zoomed-in }}=$ $\left.-0.4 * * ; \quad b^{\text {dark }}=-0.23 * * ; \quad b^{\text {sunglasses }}=-0.43 * *\right) \quad$ were significant in predicting willingness to host ( $\mathrm{H} 1$ is confirmed). The $\mathrm{R}^{2}$ is about $20 \%$ for both cases, indicating an acceptable level of explanatory power of the model [44]. Effect sizes $\left(f^{2}\right)$ for the impact of selfdisclosure strategy were small (for male guests: $\mathrm{f}^{2}$ zoomedin $=0.127 ; \mathrm{f}^{2 \text { dark }}=0.042 ; \mathrm{f}^{2}$ sunglasses $=0.061 ;$ for female guests: $\mathrm{f}^{2}$ zoomed-in $=0.138 ; \mathrm{f}^{2}$ dark $=0.046 ; \mathrm{f}^{2}$ sunglasses $=0.153$ ).

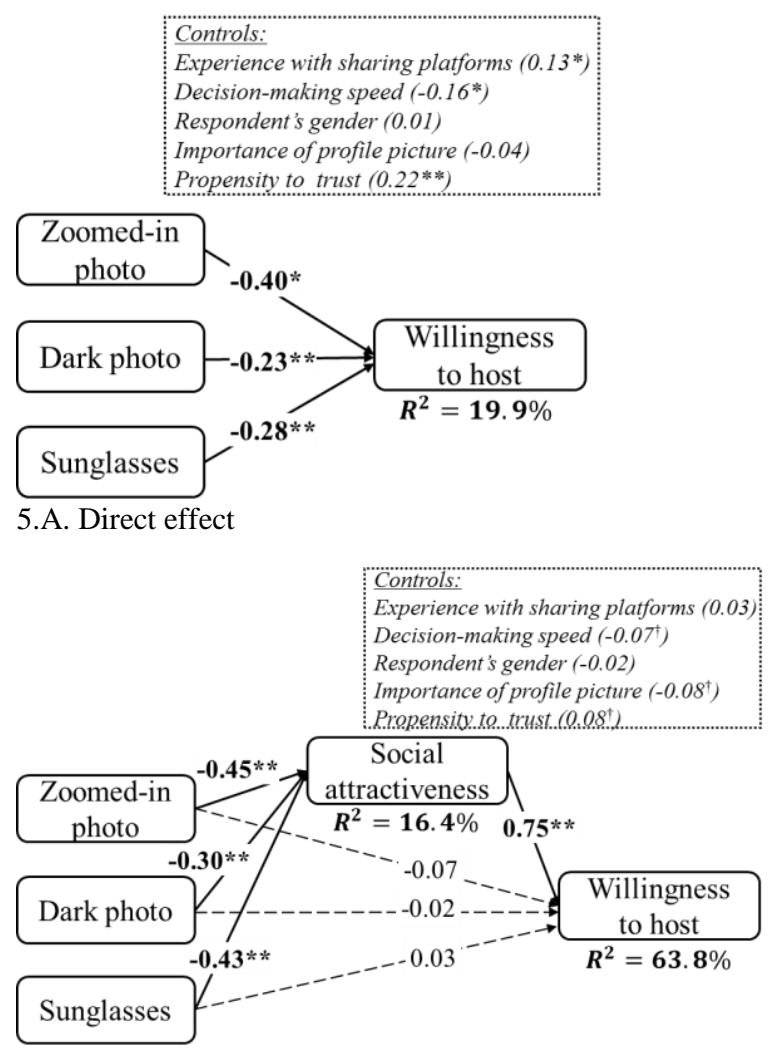

5.B. Model with a mediator

Figure 5. Mediation analysis for male guests (significance: ${ }^{* *}$ at $1 \%$ or lower, $*$ at $5 \% ;{ }^{\dagger}$ at $10 \%$ )

Second, the mediation effect of social attractiveness was assessed. One can assume mediation in the relationship between self-disclosure strategies and willingness to host if the two links were significant: 1) between a self-disclosure strategy and a mediator; and 2) between a mediator and willingness to host. The variance of willingness to host explained in the mediated model is now much higher $\left(\mathrm{R}^{2}=63.8 \%\right.$ for male guests and $\mathrm{R}^{2}=62.4 \%$ for female guests). Furthermore, the direct links from disclosure strategies to willingness to host become insignificant (for male 
guests: $b^{\text {zoomed-in }}=-0.07 ; b^{\text {dark }}=-0.02 ; b^{\text {sunglasses }}=0.03$; for female guests: $b^{\text {zoomed-in }}=-0.02 ; b^{\text {dark }}=0.05 ; b^{\text {sunglasses }}$ $=0.01)$ once social attractiveness is included. For the model with mediation, the effect sizes for the impact of self-disclosure on social attractiveness are medium (for male guests: $\mathrm{f}^{2}$ zoomed-in $=0.160$; for female guests: $\mathrm{f}^{2}$ zoomed-in $=0.204 ; \mathrm{f}^{2 \text { sunglasses }}=0.288$ ) and small (for male guests: $\mathrm{f}^{2 \text { dark }}=0.073 ; \mathrm{f}^{2 \text { sunglasses }}=0.139$; for female guests: $\mathrm{f}^{2}$ dark $=0.110$ ). Effect sizes for the impact of social attractiveness on willingness to host are large (for male guests: $\mathrm{f}^{2}=1.210$; for female guests: $\mathrm{f}^{2}=1.139$ ).

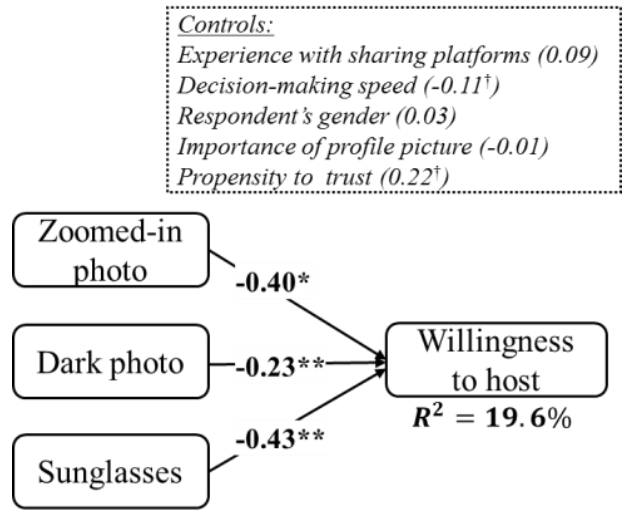

6.A. Direct effect

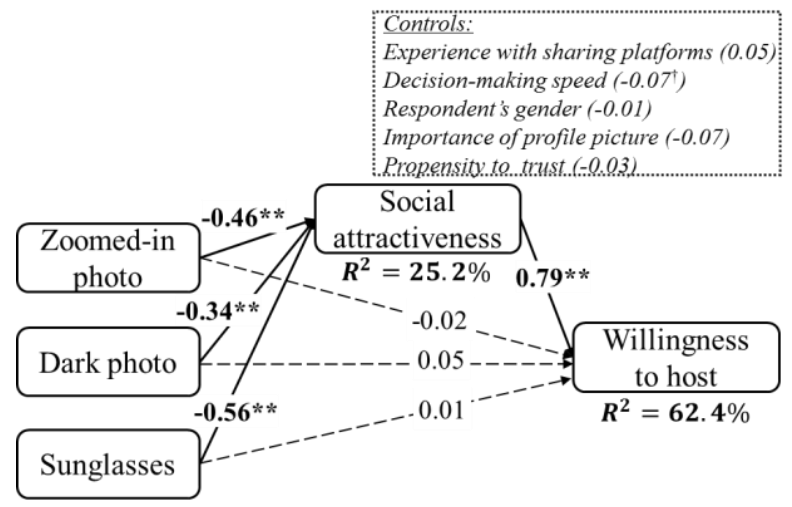

6.B. Model with a mediator

Figure 6. Mediation analysis for female guests

(significance: $* *$ at $1 \%$ or lower, $*$ at $5 \% ;{ }^{\dagger}$ at $10 \%$ )

We followed [45-46], and because the direct effect (path "disclosure strategy - willingness to host," Figure 5,6 , model 5a, 6a) was significant, we bootstrapped the sampling distribution of the indirect effect. The bootstrapping approach does not impose assumptions about the shape of the variable's distribution and showed higher levels of statistical power compared to the Sobel test [47]. After each individual path turned out to be significant, their product was computed, which represents the indirect effect. The variance accounted for (VAF), which determines the size of the indirect effect compared to the total effect (i.e., direct effect + indirect effect) is presented in Table 6. The calculated VAF hints at the link between self-disclosure strategy and willingness to host being mediated by social attractiveness ( $\mathrm{H} 2$ is supported). VAF larger than $20 \%$ and smaller than $80 \%$ characterizes partial mediation. Counter to our expectations, the respondent's gender appears to be insignificant (H3 is rejected).

Table 4. Size of the indirect effect in relation to the total effect (variance accounted for - VAF)

\begin{tabular}{|c|c|c|c|c|c|}
\hline Model & $\begin{array}{c}\text { Mediat } \\
\text { or }\end{array}$ & Predictor & $\begin{array}{l}\text { t-value } \\
\text { of the } \\
\text { indir. } \\
\text { effect }\end{array}$ & VAF & $\begin{array}{l}\text { Type } \\
\text { of } \\
\text { med. }\end{array}$ \\
\hline \multirow{3}{*}{$\begin{array}{l}\text { Willingness } \\
\text { to host a } \\
\text { male guest }\end{array}$} & \multirow{3}{*}{$\begin{array}{l}\text { Social } \\
\text { attracti- } \\
\text { veness }\end{array}$} & Zoomed-in & 6.34 & $46 \%$ & Partial \\
\hline & & Dark & 4.51 & $50 \%$ & Partial \\
\hline & & Sunglasses & 6.28 & $54 \%$ & Partial \\
\hline \multirow{3}{*}{$\begin{array}{l}\text { Willingness } \\
\text { to host a } \\
\text { female guest }\end{array}$} & \multirow{3}{*}{$\begin{array}{l}\text { Social } \\
\text { attracti- } \\
\text { veness }\end{array}$} & Zoomed-in & 7.58 & $48 \%$ & Partial \\
\hline & & Dark & 5.07 & $54 \%$ & Partial \\
\hline & & Sunglasses & 8.04 & $51 \%$ & Partial \\
\hline
\end{tabular}

We further assessed the statistical differences between parameter estimates in line with [70] and use bootstrap techniques to construct confidence intervals. For a female guest, a photo with sunglasses is perceived as significantly less socially attractive as compared to a dark photo $(\mathrm{t}=2.97, \mathrm{p}=0.003)$. Differences in coefficients when contrasting a dark photo vs. a zoomed-in photo $(\mathrm{t}=1.79, \mathrm{p}=0.074)$ or a photo with sunglasses with vs. a zoomed-in photo $(\mathrm{t}=1.36$, $\mathrm{p}=0.174$ ) were not statistically significant. For a male guest, a zoomed-in photo yielded significantly lower levels of social attractiveness than a dark photo $(t=1.98$, $\mathrm{p}=0.047)$. Differences in coefficients when contrasting a dark photo vs. a photo with sunglasses $(t=1.71$, $\mathrm{p}=0.087$ ) or a photo with sunglasses with vs. a zoomedin photo $(\mathrm{t}=-0.39, \mathrm{p}=0.697)$ were not statistically significant.

\section{Discussion and concluding remarks}

The enticement to assess strangers by their facial expressions is hard to resist in both offline and ICTmediated communication, marked by the omnipresence of images. The ecological theory explains this fact by the need to perceive - a fundamental adaptive reaction. Faced with a stimulus, perceivers aim to study it and reveal structural invariants of an object like character or ability to further estimate its affordances. Following this logic, the current study examines whether users engage in sharing transactions in line with their online facebased judgments. The ecological framework appears to be relevant. Accordingly, "it seems we are still willing to go with our own instincts about whether we think someone looks like we can trust them" [48]. Findings 
from our experimental study surmise that in the accommodation-sharing context, a photographic selfdisclosure of a guest significantly influences his or her chances to be accepted or rejected by the host. Compared to a photo with a smiling face which is positively correlated with the probability to be hosted, a face covered with the sunglasses, a zoomed-in or a dark one, ceteris paribus, significantly decreases the applicant's chances to be accepted. This link holds for both female and male guests and does not depend on the gender of a host, which contrasts the past research, which signified stronger effects for females [54]. Moreover, we demonstrate that social attractiveness judgments mediate the link between a guest's selfdisclosure and the host's willingness to cooperate. In line with previous studies postulating social attractiveness as one of the most critical traits for social and economic interactions [19-26], this principle was confirmed for sharing platforms as well.

These findings have implications for a variety of stakeholders, including platform providers, users, and scholars. For users, the results imply the importance of online presence through a photo on the sharing platforms. At the same time, not all self-disclosure is beneficial, and some choices (e.g., wearing sunglasses) can have an opposite effect. Assuming the validity of privacy calculus [49], one should carefully anticipate the possible effects of publishing a specific profile picture when looking for joint consumption. Given this, platform providers may guide their users towards uploading a "proper" profile picture, which contributes to the positive perception of other sharing economy users and thus increases the number of transactions.

The current study comes with limitations that afford opportunities for future research. First, to avoid discussion of race in the sharing economy [50-51], only white faces were used in the experiment. Second, we did not test photos of different age groups like [52], which does not allow us to conclude the possible age credits. Third, neutral treatment may enrich the findings. Based on this, a complex model describing profile picture influence on willingness to be accepted for resourcesharing can be tested in the future.

\section{Acknowledgements}

We would like to thank Tabea Müller for her support throughout the data collection process.

\section{References}

[1] C.C. Bellew, A. Todorov, "Predicting political elections from rapid and unreflective face judgments", Proceedings of the National Academy of Sciences, Washington DC (USA), 2007, pp. 17948-17953.
[2] M. Bar, M. Neta, H. Linz, "Very first impressions" Emotion. American Psychological Association, Washington DC (USA), 2006, pp. 269-278.

[3] N.O. Rule, N. Ambady, "The face of success: Inferences from chief executive officers' appearance predict company profits", Psychological science, SAGE Publications, Thousand Oaks (USA), 2008, pp. 109-111.

[4] J.Willis,A.Todorov, "First impressions:Making up your mind after a 100-ms exposure to a face",Psychological science.SAGE Publications, Thousand Oaks (USA),2006,pp. 592-598.

[5] Photofeeler:New Research Study Breaks Down "The Perfect Profile Photo" https://blog.photofeeler.com/perfect-photo (Accessed: 13.09.2018)

[6] Krisvoy, S.:Addressing Risk in the Growing Sharing Economy. Old Republic Risk Management Blog (2017), http://www.orrm.com/blog/risk-in-growing-sharing-economy (Accessed 13.09.2018)

[7] Lloyd's: Sharing risks, sharing rewards: Who should bear the risk in the sharing economy?. Innovation Report 2018, https://www.lloyds.com/news-and-risk-insight/risk-

reports/library/technology/sharing-risks-sharing-rewards (Accessed: 12.09.2018)

[8] A.N.Joinson, C.Paine,T.Buchanan,U.D.Reips. "Measuring self-disclosure online: Blurring and non-response to sensitive items in web-based surveys", Computers in Human Behavior, Elsevier, Amsterdam (Netherlands), 2008, pp. 2158-2171.

[9] D.Tingley,"Face-off: Facial Features and Strategic Choice", Political Psychology, Wiley-Blackwell, Hoboken (USA), 2014, pp. 35-55.

[10] M. Van't Wout, A.G.Sanfey, “Friend or foe: The effect of implicit trustworthiness judgments in social decisionmaking", Cognition, Elsevier, Amsterdam (Netherlands), 2008, pp. 796-803.

[11] L.Z. McArthur, R.M. Baron, "Toward an ecological theory of social perception",Psychological review,1983,p.215. [12] Gibson, J.J., The ecological approach to visual perception, Houghton Mifflin Company, Boston (USA), 1979. [13] D.S. Berry, L.Z. McArthur, "Perceiving character in faces: the impact of age-related craniofacial changes on social perception", Psychological bulletin. American Psychological Association, Washington DC (USA), 1986, pp. 3-18.

[14] Zebrowitz, L.A., New directions in social psychology. Reading faces: Window to the soul?,Westview Press, Boulder (USA), 1997.

[15] M.T. Balaban, "Affective influences on startle in fivemonth-old infants: Reactions to facial expressions of emotion.", Child development. Wiley-Blackwell, Hoboken (USA), 2014, pp. 35-55.

[16] A.A. Marsh, N. Ambady, R.E. Kleck, "The effects of fear and anger facial expressions on approach-and avoidancerelated behaviors",Emotion,American Psychological Association, Washington DC (USA), 2005, pp. 119-124.

[17] C. Rezlescu, B. Duchaine, C.Y. Olivola, N. Chater, "Unfakeable Facial Configurations Affect Strategic Choices in Trust Games with or without Information about Past Behavior", PLoS ONE. Public Library of Science, San Francisco (USA), 2012.

[18] A.H. Eagly, R.D. Ashmore, M.G. Makhijani, L.C. Longo, "What is beautiful is good, but...: A meta-analytic review of 
research on the physical attractiveness stereotype", Psychological bulletin. American Psychological Association, Washington DC (USA), 1991, pp. 109-128.

[19] R.L. Dipboye, R.D. Arvey, D.E. Terpstra, "Sex and physical attractiveness of raters and applicants as determinants of resume evaluations", Journal of Applied Psychology, American Psychological Association, Washington DC (USA), 1977, pp. 288-294.

[20] D.A. Miller, D.K. Routh, "Where women win: Supervisors of school psychologists prefer female job candidates", American Psychological Association, Washington DC (USA), 1985, pp. 42-49.

[21] M. Snyder, M. Rothbart, "Communicator attractiveness and opinion change" Canadian Journal of Behavioral Science, American Psychological Association, Washington DC (USA), 1971, pp. 377-387.

[22] L.A.Jackson, "The influence of sex,physical attractiveness,sex role,and occupational sex-linkage on perceptions of occupational suitability" Journal of Applied Social Psychology.Wiley-Blackwell,Hoboken(USA), 1983, pp. 31-44.

[23] L.M. Drogosz, P.E. Levy, "Another look at the effects of appearance, gender, and job type on performance-based decisions" Psychology of Women Quarterly. SAGE Publications, Thousand Oaks (USA), 1996, pp. 437-445.

[24] C. Shahani, R.L.Dipboye,T.M.Gehrlein, “Attractiveness bias in the interview: Exploring the boundaries of an effect",Basic and Applied Social Psychology,Taylor \& Francis, Thames (UK),1993,pp.317-328.

[25] S.J.Solnick,M.E.Schweitzer,"The influence of physical attractiveness and gender on ultimatum game decisions", Organizational Behavior and Human Decision Processes,Elsevier,Amsterdam(Netherlands),1999,p.199-215. [26] W.A.Castellow,K.L.Wuensch,C.H.Moore,"Effects of physical attractiveness of the plaintiff and defendant in sexual harassment judgments",Journal of Social Behavior and Personality,Palmerston North (New Zealand),1990,pp.547562.

[27] J.A.Simpson,B.A.Harris, "Interpersonal attraction." (1994).

[28] J.Hamari, M.Sjöklint,A.Ukkonen."The sharing economy: Why people participate in collaborative consumption.", Journal of the association for information science and technology, Association for Information Systems, 2016, pp. 2047-2059.

[29] B. Balck, D. Cracau, "Empirical analysis of customer motives in the share conomy: a cross-sectoral comparison", Otto-von-Guericke University Magdeburg, Faculty of Economics and Management, 2015.

[30] C.L. Toma, J.T. Hancock, N.B. Ellison, "Separating Fact From Fiction: An Examination of Deceptive Self-Presentation in Online Dating Profiles", Personality and Social Psychology Bulletin. SAGE Publications, Thousand Oaks (USA), 2008, pp. 1023-1036.

[31] J.B. Walther, "Interpersonal effects in computermediated interaction: A relational perspective", Communication research, SAGE Publications, Thousand Oaks (USA), 1992, pp. 52-90.

[32] J.B. Walther, "Computer-mediated communication: Impersonal, interpersonal, and hyperpersonal
interaction",Communication research, SAGE Publications, Thousand Oaks (USA), 1996, pp. 3-43

[33] M. Weisbuch, Z. Ivcevic, N. Ambady, "On being liked on the web and in the "real world": Consistency in first impressions across personal webpages and spontaneous behavior", Journal of Experimental Social Psychology, Elsevier, Amsterdam (Netherlands), 2009, pp. 573-576.

[34] Airbnb.com, https://www.airbnb.com (Accessed: 12.09.2018)

[35] P. Chatterjee, "Online reviews: do consumers use them?" (2001).

[36] Blal, M. C. Sturman. "The differential effects of the quality and quantity of online reviews on hotel room sales", Cornell Hospitality Quarterly, SAGE Publications, Thousand Oaks (USA), 2014, pp. 365-375.

[37] D.H. McKnight, V. Choudhury, C. Kacmar, "Developing and validating trust measures for e-commerce: An integrative typology", Information Systems Research, Institute for Operations Research and the Management Sciences, Cantonsville (USA), 2002, pp. 334-359.

[38] C. Fornell, F.L. Bookstein, "Two structural equation models: LISREL and PLS applied to consumer exit-voice theory", Journal of Marketing Research, SAGE Publications, Thousand Oaks (USA), 1982, pp. 440-452.

[39] Ringle, C. M., Wende, S., and Becker, J.-M. 2015. "SmartPLS 3." Boenningstedt: SmartPLS GmbH, http://www.smartpls.com.

[40] C. Homburg, A. Giering, "Konzeptualisierung und Operationalisierung komplexer Konstrukte", MarketingZeitschrift für Forschung und Praxis, Verlag C.H. Beck, Munich (Germany), 1996, pp. 5-24.

[41] J. Hulland, "Use of partial least squares (PLS) in strategic management research: A review of four recent studies", Strategic Management Journal, John Wiley \& Sons, Hoboken (USA), 1999, pp.195-204.

[42] C. Fornell, D.F. Larcker, "Structural Equation Models with Unobservable Variables and Measurement Errors", Journal of Marketing Research, SAGE Publications, Thousand Oaks (USA), 1981, pp. 39-50 .

[43] Nunnally, J.C., Psychometric theory, McGraw-Hill, New York, 1978.

[44] R.F. Falk, N.B Miller, “A primer for soft modeling”, University of Akron Press, Akron (USA), 1992.

[45] K.J. Preacher, A.F. Hayes, "SPSS and SAS procedures for estimating indirect effects in simple mediation models", Behavior research methods, instruments, \& computers, Springer Science + Business Media, Heidelberg (Germany), 2004, pp. 717-731.

[46] Preacher, K J., and A. F. Hayes. "Assessing mediation in communication research", The Sage sourcebook of advanced data analysis methods for communication research, Sage Publications, Thousand Oaks (USA), 2008.

[47] Hair Jr, J.F., et al. A primer on partial least squares structural equation modeling (PLS-SEM). Sage Publications, Thousand Oaks (USA), 2016.

[48] Live Science: Looks Overshadow Reputation When Deciding Who To Trust (2012), https://www.livescience.com/20311-trustworthiness-productreputation.html (Accessed: 13.09.2018)

[49] T. Dinev, P. Hart. "An extended privacy calculus model for e-commerce transactions.”, Information systems research, 
Institute for Operations Research and the Management Sciences, Cantonsville (USA), 2006, pp. 61-80.

[50] B.G.Edelman,M.Luca,D.Svirsky, "Racial Discrimination in the Sharing Economy: Evidence from a Field Experiment", Working Paper 16-069. Harvard Business School (2015).

[51] V. Kakar, J. Voelz, J. Wu, J. Franco, "The Visible Host: Does Race Guide Airbnb Rental Rates in San Francisco?", Journal of Housing Economics, Elsevier, Amsterdam (Netherlands), 2018, pp. 25-40.

[52] T. Ramos, M. Oliveira, A.S. Santos, L. Garcia-Marques, P. Carneiro, "Evaluating young and old faces on social dimensions: Trustworthiness and dominance", Psicológica. Universitat di Valencia, Valencia (Spain), 2016.

[53] E. Ert, A. Fleischer, N. Magen, "Trust and reputation in the sharing economy: The role of personal photos in Airbnb", Tourism Management, Elsevier, Amsterdam (Netherlands), 2016, pp. 62-73.

[54] Fagerstrøm, S. Pawar, V. Sigurdsson, G.R. Foxall, M. Yani-de-Soriano, "That personal profile image might jeopardize your rental opportunity! On the relative impact of the seller's facial expressions upon buying behavior on Airbnb"T", Computers in Human Behavior, Elsevier, Amsterdam (Netherlands), 2017, pp. 123-131.

[55] Derbaix, J. Bree, "The impact of children's affective reactions elicited by commercials on attitudes toward the advertisement and the brand", International Journal of Research in Marketing, Elsevier, Amsterdam (Netherlands), 1997, pp. 207-229.

[56] D.A. Small, N.M. Verrochi, "The face of need: Facial emotion expression on charity advertisements", Journal of Marketing Research, SAGE Publications, Thousand Oaks (USA), 2009, pp. 777-787.

[57] R.J. Tanner, A. Maeng, "A tiger and a president: Imperceptible celebrity facial cues influence trust and preference", Journal of Consumer Research, University of Chicago Press, Chicago (USA), 2012, 769-783.

[58] M. Gabbott, G. Hogg, "An empirical investigation of the impact of non-verbal communication on service evaluation", European Journal of Marketing, Emerald Publishing Limited, Bingley (UK), 2000, 384-398.

[59] N.C. Krämer, S. Winter, "Impression management 2.0: The relationship of self-esteem, extraversion, self-efficacy, and self-presentation within social networking sites", Journal of media psychology, Hogrefe Publishing Group, Boston (USA), 2008, pp. 106-116.

[60] P.M. Niedenthal, M. Brauer, J.B. Halberstadt, Å. H. Innes-Ker, "When did her smile drop? Facial mimicry and the influences of emotional state on the detection of change in emotional expression", Cognition \& Emotion, Taylor \& Francis, Thames (UK), 2001, pp. 853-864.

[61] J.L. Tracy,R.W. Robins, "Show your pride:Evidence for a discrete emotion expression", Psychological Science, SAGE Publications, Thousand Oaks (USA),2004,pp.194-197.

[62] T.M. Lee, H.L. Liu, R. Hoosain, W.T. Liao, C. T.Wu, K.S. Yuen, \& J.H. Gao "Gender differences in neural correlates of recognition of happy and sad faces in humans assessed by functional magnetic resonance imaging", Neuroscience letters, Elsevier, Amsterdam (Netherlands), 2002, pp. 13-16.

[63] H. Critchley, E. Daly, M. Phillips, M. Brammer, E. Bullmore, S. Williams \& D. Murphy, "Explicit and implicit neural mechanisms for processing of social information from facial expressions: a functional magnetic resonance imaging study", Human brain mapping, John Wiley \& Sons, Hoboken (USA), 2000, pp. 93-105.

[64]D.Cyr,M.Head,H.Larios,B.Pan, "Exploring human images in website design: a multi-method approach", MIS quarterly, University of Minesota, Minneapolis(USA),2009,pp.539-566. [65] L. Liu, D. Preotiuc-Pietro, Z.R.Samani, M. E. Moghaddam, L. Ungar, "Analyzing personality through social media profile picture choice." In Tenth international AAAI conference on web and social media, 2016.

[66] Bakhshi, S., Shamma, D. A., E. Gilbert, "Faces engage us: Photos with faces attract more likes and comments on instagram", In Proceedings of the SIGCHI Conference on Human Factors in Computing Systems ,2014, pp. 965-974.

[67] Siibak, "Constructing masculinity on a social networking site: The case-study of visual self-presentations of young men on the profile images of SNS Rate", Young, SAGE Publications, Thousand Oaks (USA), 2006, pp. 403-425.

[68] F. Hawlitschek, T.Teubner, H. Gimpel, H., "Consumer motives for peer-to-peer sharing", Journal of Cleaner Production, Elsevier, Amsterdam (Netherlands), 2018, pp. 144-157.

[69] K. Erickson, J.Schulkin,"Facial expressions of emotion:A cognitive neuroscience perspective",Brain and Cognition, Elsevier,Amsterdam (Netherlands),2018,pp.52-60.

[70] M. Rodríguez-Entrena, F. Schuberth, C. Gelhard, "Assessing statistical differences between parameters estimates in Partial Least Squares path modeling", Quality \& quantity, Springer Science + Business Media, Heidelberg (Germany), 2018, pp. 57-69.

[71] M. Walker, T. Vetter, "Changing the personality of a face: Perceived Big Two and Big Five personality factors modeled in real photographs", Journal of Personality and Social Psychology, American Psychological Association, Washington DC (USA), 1986, pp. 609-624.

[72] M. Cheng, C. Foley, "The sharing economy and digital discrimination: The case of Airbnb", International Journal of Hospitality Management, Elsevier, Amsterdam (Netherlands), 2018, pp. 95-98.

[73] J.A. Hall, J.D. Carter, T.G. Horgan, "Gender differences in nonverbal communication of emotion", Gender and emotion: Social psychological perspectives, Cambridge University Press, New York (USA), 2000, pp. 97-117.

[74] J.A. Hall, D. Matsumoto, "Gender differences in judgments of multiple emotions from facial expressions", Emotion, American Psychological Association, Washington DC (USA), 2005, pp. 201.

[75] H. Hoffmann , H. Kessler, T. Eppel, S. Rukavina \& H.C. Traue, "Expression intensity, gender and facial emotion recognition: Women recognize only subtle facial emotions better than men", Acta psychologica, Elsevier, Amsterdam (Netherlands), 2010, pp. 278-283.

[76] R.M. Baron, D.A. Kenny, "The moderator-mediator variable distinction in social psychological research: Conceptual, strategic, and statistical considerations", Journal of personality and social psychology, American Psychological Association, Washington DC (USA), 1986, pp. 1173.

[77] D. J. Hauser, P. C. Ellsworth, R. Gonzalez, R. "Are manipulation checks necessary?", Frontiers in psychology, 2018 